\title{
The Beneficial Effects of Sitagliptin, a Dipeptedyl Peptidase-4 (DPP-4) Inhibitor on Experimentally Induced Non-Alcoholic Fatty Liver Disease in Rats
}

\author{
HEBAT ALLAH M. MAHMOUD, M.Sc.*; FATMA A. MAHMOUD, M.D.*; \\ GHADA HASHEM, M.D.*; HANAN H. AHMED, M.D.** and HESHAM M. MAHMOUD, M.D.* \\ The Departments of Medical Pharmacology* and Biochemistry**, Faculty of Medicine, Cairo University
}

\begin{abstract}
Background: Non alcoholic fatty liver disease (NAFLD) is an increasing health problem which affects about $1 / 3$ of the population worldwide, it is strongly associated with metabolic syndrome with oxidative stress and insulin resistance are the mechanisms mostly involved in its pathogenesis. Dipeptidyl peptidase- 4 inhibitors are antidiabetic agents expected to have beneficial effects beyond their glycemic control.
\end{abstract}

Aim of the Study: The present work was designed to study the beneficial effects of sitagliptin (a DPP-4I) on a dietary model of NAFLD.

Material and Methods: 30 male albino rats were allocated in 3 groups. The effects of sitagliptin, was assessed in groups III. Body weight and blood pressure were recorded and blood samples were tested for total cholesterol, triglycerides and liver transaminases, glucose and insulin levels. Livers for GSH, MDA, TGF-B and DPP-4 activity and for histopatholgical examination. Aortae were removed for in vitro vascular reactivity studies.

Results: Induction of NAFLD model by HFD for 20 weeks resulted in significant increase in body weight, blood pressure, liver index and epididymal weight. Significant reduction of these parameters was observed with 4 week treatment with sitagliptin. There was significant increase in all biochemical parametres in HFD fed rats compared to that of normal with significant improvement in sitagliptin treated group. HFD model groups showed notable steatosis, lobular inflammation and fibrosis which was improved with sitagliptin use. Also NAFLD rats developed endothelial dysfunction which was significantly ameliorated in sitagliptin treated group.

Conclusion: The results of the present work showed that the DPP4Is have the potential to favorably influence the course of NAFLD process and its complications. DPP4I (sitagliptin) has many beneficial effects including scavenging of free radicals, and enhancing the activity of antioxidant effects. Large clinical trials are needed to determine the effectiveness of DPP-4 inhibitors for the prevention and treatment of NAFLD

Correspondence to: Dr. Hebat Allah M. Mahmoud, The Department of Medical Pharmacology, Faculty of Medicine, Cairo University
Key Words: Non alcoholic fatty liver disease - HFD - DPP4Is - Sitagliptin.

\section{Introduction}

NON ALCOHOLIC fatty liver disease (NAFLD) is one of the most common causes of chronic liver disease worldwide which used to be considered the leading cause of chronic liver damage in the Western countries and with the spread of westernized life style, NAFLD is exhibiting an increasingly universal distribution [1]

NAFLD encompasses a wide spectrum of liver diseases ranging from simple steatosis to nonalcoholic steatohepatitis, which may progress to liver cirrhosis, potentially leading to decompensated liver disease, hepatocellular carcinoma (HCC) and liver related mortality [2].

NAFLD is strongly associated with several aspects of metabolic syndrome, i.e., obesity, dyslipidemia, insulin resistance and concomitant glucose intolerance, including T2DM [3]. Therefore, improvement of these medical conditions may be beneficial to ameliorate NAFLD.

Treatment of NAFLD includes sustained weight loss which seems to improve insulin resistance associated with NAFLD. Several pharmacological agent have been studied including insulin sinsitizing agents, lipid lowering agents, antioxidants, probiotics and cytoprotectives.

Sitagliptin, a dipeptidyl peptidase 4 (DPP4) inhibitor, is a new class of antidiabetic agents commonly used in practice in treatment of T2DM. It is one of the best known glucagon like peptide 1 
(GLP1), enhancers, due to the inhibition of DPP4 activity, which is responsible for the degradation of GLP1 [4].

Recently, incretins have been reported to have various bioactivities, not only in pancreas cells, but also outside the pancreas. Moreover, several studies have revealed the potential role of incretin based therapies in treatment of NAFLD (Klein et al., 2014). DPP4 inhibitors may be able to attenuate the pathology of NAFLD in patient because it was found that these patient have increased DPP4 activity. Sitagliptin has been shown to prevent the development of hepatic steatosis induced by a fructose rich diet. However, the beneficial effects of DPP4 inhibition on diet induced effects, especially on liver tissue inflammation, fibrosis, oxidative stress remains poorly understood [5]

\section{Material and Methods}

The study was conducted in the Pharmacology Department, Faculty of Medicine, Cairo University in a duration of 5 months started from March 2016 to the end of July 2016.

\section{Drugs and chemicals used:}

Sitagliptin Merck Sharp \& Dohme (Italy) a subsidiary of Merck \& Co., Inc. (MSD Company) powder dissolved in distilled water. It was given to rats by means of oral gavage in a dose of $10 \mathrm{mg} /$ $\mathrm{kg} /$ day in a total volume of $1 \mathrm{ml}$ [6].

\section{High fat diet (HFD):}

Consists of the standard crushed rat chow diet plus 10\% animal fat and 2\% cholesterol (SigmaAldrich-Egypt), [9].

\section{Phenylephrine (Sigma-Aldrich-Egypt):}

The drugs were supplied in powder form and were freshly prepared in distilled water.

Krebs solution: For use in the in-vitro experiments on isolated aortic ring preparation. It has the following composition per liter distilled water

$\mathrm{NaCl} 5.5 \mathrm{~g} / \mathrm{l}-\mathrm{KCl} 0.35 \mathrm{~g} / \mathrm{l}-\mathrm{CaCl} 20.28 \mathrm{~g} / 1-$ $\mathrm{MgSO} 4$ 0.14g/l - KH2PO4 0.16g/l - NaHCO3 2.1g/l - Glucose 2g/l.

Kits:

- Serum Cholesterol \& Triglyceride assessment Kit, SIGMA-Aldrich-Egypt.

- Alanine Aminotransferase (ALT) \& Aspartate Aminotransferase (AST) Activity Assay Kit SIGMA-Aldrich-Egypt.
- Serum insulin ELISA Kit (Ray Bio®- Rat Insulin, USA).

- Glucose Assay Kit (Sigma-Aldrich-Egypt).

- Malondialdehyde (MDA) (Ray Bio® Rat MDA, USA).

- Tissue reduced glutathione GSH ELISA kit (Ray Bio®- Rat GSH, USA).

- Tissue Transforming Growth Factor-B (TGF-B) ELISA kit (RayBio®)- Rat TGF-B, USA). Growth Factor-B (TGF-B) ELISA kit (RayBio ${ }^{\circledR}-$ Rat TGF-B, USA).

- Dipeptidyl peptidase-4 (DPP4) Activity Assay Kit (Ray Bioß- Rat DPP4, USA).

Animals used:

This study included 30 adult male albino rats with an average weight of 180-200g. The animals were kept on a1 2-h light/dark cycle (lights on from 08:00am) at a constant ambient temperature $\left(24 \pm 1^{\circ} \mathrm{C}\right)$, The animals were handled according to the guide lines of local ethical committee which comply with the international laws for use and care of laboratory animals. The animals were divided into 5 groups (12 rats each).

\section{Group I (Negative control group):}

Rats were fed with the standard rat chow for 16 weeks and $1 \mathrm{ml} / \mathrm{kg} /$ day of distilled water were administrated orally to these animals for additional 4 weeks which served as a negative control

Group II (Animal model of high fat diet (HFD) induced non-alcoholic fatty liver disease (positive control):

Rats had free access to modified HFD in pellet form for 20 weeks with oral distilled water $(1 \mathrm{ml} / \mathrm{kg} /$ day) in the last 4 weeks [7].

\section{Group III:}

Rats received the HFD for 20 weeks with administration of sitagliptin in a dose of $10 \mathrm{mg} / \mathrm{kg} /$ day by means of oral gavage together with (HFD) daily for the last 4 weeks [6].

\section{Methods:}

The HFD was prepared by mixing $2 \mathrm{~g}$ cholesterol and $10 \mathrm{~g}$ animal fat with $88 \mathrm{~g}$ normal crushed pellet chow. The HFD was composed of the following energy sources: $52 \%$ was provided by carbohydrates, $30 \%$ by fat, and $18 \%$ by protein(overall calories: $4.8 \mathrm{kcal} / \mathrm{g}$ ). The negative control rats were fed normal rat pellet chow, which contains $67 \%$ carbohydrates, $10 \%$ fat, and $23 \%$ protein as the energy sources (overall calorie: $3.6 \mathrm{kcal} / \mathrm{g}$ ) [7]. 


\section{Outcome measures:}

a- In vivo measures:

Body weight recordings were done to rats of all groups at the beginning and at the end of the study.

Blood pressure was monitored; at the beginning of the study and at the end using the non-invasive rat tail cuff blood pressure measuring system (Harvard Apparatus Ltd, Edenbridge, Kent, England). In the tail-cuff technique, animals were warmed for $30 \mathrm{~min}$ at $28^{\circ} \mathrm{C}$ in a thermostatically controlled heating cabinet (UgoBasille, Italy) for detection of tail artery pulse, the tail was passed through a miniaturized cuff and a tail-cuff sensor that was connected to an amplifier (ML 125 NIBP, AD Instruments, Australia).

- Mean arterial pressure (MAP) was calculated using the equation:

- MAP = Diastolic blood pressure $+1 / 3$ (systolic blood pressure-diastolic blood pressure).

\section{b- Collection of blood samples for biochemical analysis:}

Venous blood samples were obtained from all animals at the end of the experiment.

\section{Procedure:}

The animals were lightly anaesthetized then venous samples were collected by means of capillary glass tubing from the retro-orbital plexus. Serum samples were analyzed for the measurement of:

- Serum total cholesterol (TC), Serum triglyceride (TG).

- Serum alanine aminotransferase (ALT), serum aspartate aminotransferase (AST).

- Serum insulin level, fasting blood glucose.

c- Determination of liver index, oxidant, antioxidant parameters, level of TGF-B and DPP-4 activity:

Liver was quickly removed and weighed for calculation of liver index (LI), it is calculated as liver weight/body weight $\times 100 \%$ ).

Part of the liver tissues was snap frozen in liquid nitrogen for analysis of:

- Hepatic levels of malondialdehyde (MDA).

- Hepatic levels of reduced glutathione (GSH).

- Hepatic levels of transforming growth factor B (TGF-B).

- Hepatic levels of DPP-4.

\section{$d$ - Determination of visceral obesity:}

The epididymal fat was removed and measured, and used as an indicator for visceral adipose tissue.

\section{e-Pathological examination:}

A small piece of liver was immediately fixed in $10 \%$ neutral-buffered formalin then embedded in paraffin wax. For light microscopic analysis of liver histology, the paraffin-embedded liver tissues were cut into $4 \mu \mathrm{m}$ sections, and standard hematoxylin-eosin (H\&E) staining was performed. Hepatic fibrosis was assessed by Masson trichrome stain.

The liver sections were scored according to the NAFLD Activity Score (NAS), which includes the features of active liver injury. The score is defined as the sum of the scores for steatosis (0-3) hepatic steatosis: Score 0, no fat; score 1, steatosis occupying less than $33 \%$ of the hepatic parenchyma; score $2,34-66 \%$ of the hepatic parenchyma; score 3 , more than $66 \%$ of the hepatic parenchyma, lobular inflammation (0-3) inflammatory cell infiltration: Score 0: None; score 1, 1-2 foci/field; score 2,3-4 foci/field; score 3, more than 4 foci/field, and hepatocellular ballooning (0-2); is evaluated for zonal location, and the estimate of its severity is based on the numbers of hepatocytes showing this abnormality (score $1=$ few ballooned cells, score $2=$ marked ballooning) thus ranging from 0 to 8 [8].

The staging of hepatic fibrosis was investigated by Masson staining as:

- Stage 1: Perisinusoidal/pericellular fibrosis; focally or extensively present (lesion in the central vein area).

- Stage 2: Zone 3 perisinusoidal/pericellular fibrosis with focal or extensive periportal fibrosis (lesion in the central vein area and expansion to thesurrounding area).

- Stage 3: Portal fibrosis with focal or extensive bridging fibrosis.

- Stage 4: Cirrhosis. Table (4) [8,9].

\section{f- In vitro study:}

Vascular reactivity studies of isolated rat aorta to examine endothelial dysfunction induced by HFD.

Rats were anesthetized with intraperitoneal sodium pentobarbital $(35 \mathrm{mg} / \mathrm{kg})$ then sacrificed. The thoracic aorta was quickly removed, cleaned of adhering fat and connective tissue. Ring segments $(3-5 \mathrm{~mm})$ were mounted between two stainless steel wires in 10-ml organ baths filled with 
modified Krebs solution, under passive tension of $1 \mathrm{~g}$ for $45 \mathrm{~min}$. The rings were maintained at $37^{\circ} \mathrm{C}$ and gassed with a $95 \% \mathrm{O} 2$ and $5 \% \mathrm{CO} 2$ mixture $(\mathrm{pH}=7.4)$. The contractile response (isometric tension, in $\mathrm{g}$ ) was measured by a force transducer coupled to data acquisition system and analysis software (powerlab) ADInstruments. Organ bath 4/30, ML221 (Australia) transducer (TR 1201Pan lab, Spain).

After 45 minutes of equilibration; aortic rings were challenged with phenylephrine to assure the good contractile condition of the preparation [10] A dose response curve of the preparation from different groups was done to Phenylephrine induced contractile response

\section{Statistical analysis:}

The data was coded and entered using the statistical package SPSS version 15 . The data was presented as: Mean and standard deviation, for quantitative variables and number and percentage for qualitative values. Statistical differences between groups were tested using Chi Square test for qualitative variables, independent sample $t$ test and ANOVA (analysis of variance) test with post Hoc Bonferroni test for quantitative variables. nificant.

$p$-value $<0.05$ was considered statistically sig-

\section{Results}

The body weight (BW) changes and the mean arterial pressure were measured to all rats of the study groups at the beginning and the end of the study.

Feeding rats with high fat diet (HFD) for 20 weeks in group II resulted in significant increase in the mean body weight and the mean arterial pressure (MAP) at the end of the 20th week compared to that of the control group. Administration of sitagliptin for 4 weeks resulted in a significant reduction of the mean $\mathrm{BW}$ and an insignificant change of the mean (MAP (Tables 1,2).

Feeding rats with HFD resulted in increase in visceral adiposity as indicated with significant increase in epididymal fat weight and liver index compared to that of control group. Treatment with sitagliptin resulted in significant reduction of epidydimal fat weight and liver index compared to HFD fed non treated group (Table 3).

Regarding the different biochemical parameters, feeding rats with HFD for 20 weeks (group II) resulted in significant elevation of fasting blood glucose level with significant rise of serum insulin level as well as significant elevation of serum cholesterol and triglesyrides, there was also significant elevation of serum liver enzymes ALT, AST compared to that of the normally fed control rats.

Giving sitagliptin orally for 4 weeks resulted in significant reduction of fasting blood glucose and serum insulin levels.

Giving sitagliptin resulted significant reduction of serum cholesterol, triglyserides and AST, ALT compared to HFD fed non treated group.

Regarding the oxidant antioxidant parameters measured in liver tissue there was significant elevation of hepatic MDA levels and significant reduction of reduced glutathione levels (GSH) in liver tissue of rats of HFD fed non treated group compared to the normal control with significant reduction of MDA levels and significant elevation of GSH levels with treatment with sitagliptin.

Feeding rats with HFD for 20 weeks resulted in significant elevation of hepatic TGF-B and DPPIV levels compared to normally fed control group, with significant reduction of their values with treatment with sitagliptin compared to HFD fed non treated group (Table 4).

Table (1): Effect of treatment with sitagliptin (10mg/kg/day) together with high fat diet HFD for 4 week preceded by 16 weeks of HFD only on the mean body weight of albino rats.

\begin{tabular}{|c|c|c|}
\hline \multicolumn{3}{|c|}{ The mean body weight $(\mathrm{g}) \pm \mathrm{SD}$} \\
\hline Groups & At the beginning & $\begin{array}{l}\text { At the end } \\
\text { of } 20 \text { th week }\end{array}$ \\
\hline Group I (control) & $191 \pm 8.43$ & $371 \pm 9.5$ \\
\hline Group II (HFD) & $193.3 \pm 8.5$ & $438.3 \pm 12.3 *$ \\
\hline $\begin{array}{l}\text { Group III } \\
\text { (sitagliptin treated) }\end{array}$ & $193.4 \pm 9.2$ & $396.3 \pm 11.4 \#$ \\
\hline \multicolumn{3}{|c|}{$\begin{array}{l}\text { Data are represented as mean } \pm \text { SD. } \\
\mathrm{n}=10 \text {. } \\
*=\text { Significant change compared to group I }(p \text {-value }<0.05) \text {. } \\
\#=\text { Significant change compared to group II }(p \text {-value }<0.05) .\end{array}$} \\
\hline \multicolumn{3}{|c|}{$\begin{array}{l}\text { Table (2): Effect of treatment with sitagliptin }(10 \mathrm{mg} / \mathrm{kg} / \mathrm{day}) \\
\text { together with high fat diet HFD for } 4 \text { week preceded } \\
\text { by } 16 \text { weeks of HFD only on the mean arterial } \\
\text { pressure (MAP) of albino rats. }\end{array}$} \\
\hline
\end{tabular}

The mean value of the mean arterial pressure (MAP) (mm hg) \pm SD

\begin{tabular}{lcc}
\hline Groups & At the beginning & $\begin{array}{c}\text { At the end } \\
\text { of } 20^{\text {th }} \text { week }\end{array}$ \\
\hline Group I (control) & $86.08 \pm 1.49$ & $87.91 \pm 1.44$ \\
Group II (HFD) & $86.25 \pm 1.92$ & $143.55 \pm 5.28^{*}$ \\
Group III & $86.5 \pm 1.8$ & $133.66 \pm 5.86$ \\
(sitagliptin treated) & & \\
\hline
\end{tabular}

Data are represented as mean $\pm \mathrm{SD}$

$\mathrm{n}=10$

*=Significant change compared to group I ( $p$-value <0.05) 
Table (3): Effect of treatment with sitagliptin (10 mg/kg/day) together with high fat diet HFD for 4 week preceded by 16 weeks of HFD only on epididymal fat weight and liver index of albino rats.

\begin{tabular}{lcc}
\hline Groups & Epididymal fat weight $(\mathrm{g})$ & Liver index $\%$ \\
\hline Group I (control) & $7.71 \pm 0.74$ & $3.00 \pm 0.25$ \\
Group II (HFD) & $11.68 \pm 0.51^{*}$ & $4.79 \pm 0.470^{*}$ \\
Group III (sitagliptin treated) & $9.91 \pm 0.401 \#$ & $3.93 \pm 0.249 \#$ \\
\hline $\begin{array}{l}\text { Data are represented as mean } \pm \text { SD. } \\
\mathrm{n}=10 .\end{array}$ & * = Significant change compared to group I $(p$-value $<0.05)$. \\
\cline { 2 - 2 } & \# = Significant change compared to group II $(p$-value $<0.05)$.
\end{tabular}

Table (4): Effect of treatment with sitagliptin (10 mg/kg/day) together with high fat diet HFD for 4 week preceded by 16 weeks of HFD only on serum and tissue biochemical parameters in albino rats.

\begin{tabular}{llcc}
\hline & $\begin{array}{l}\text { Normal } \\
\text { control }\end{array}$ & \multicolumn{1}{c}{$\begin{array}{c}\text { HFD non } \\
\text { treated }\end{array}$} & $\begin{array}{c}\text { Sitagliptin } \\
\text { treated }\end{array}$ \\
\hline Fasting blood glucose $\mathrm{mg} / \mathrm{dl}$ & $85.67 \pm 4.65$ & $285.85 \pm 15.0^{*}$ & $214.39 \pm 12.70 \#$ \\
Serum insulin $\mathrm{Pg} / \mathrm{ml}$ & $759.11 \pm 44.42$ & $1949 \pm 74.46^{*}$ & $1388.2 \pm 70.99 \#$ \\
Total cholesterol mg/dl & $73.55 \pm 6.47$ & $266.38 \pm 7.26^{*}$ & $208.71 \pm 11.36 \#$ \\
Triglycerides $\mathrm{mg} / \mathrm{dl}$ & $71.42 \pm 9.66$ & $142.11 \pm 7.53^{*}$ & $102.45 \pm 5.61 \#$ \\
ALT U/ml & $39.08 \pm 5.7$ & $143.94 \pm 9.77^{*}$ & $111.1 \pm 7.72 \#$ \\
AST U/ml & $26.61 \pm 3.97$ & $164.99 \pm 9.08^{*}$ & $120.23 \pm 9.57 \#$ \\
Hepatic MDA nmol/g tissue & $247.78 \pm 17.04$ & $504.4 \pm 43.56^{*}$ & $393.8 \pm 21.53 \#$ \\
Hepatic GSH U/g tissue & $494.46 \pm 14.40$ & $277.51 \pm 17.75^{*}$ & $347.0 \pm 30.19 \#$ \\
TGF-B ng/g tissue & $5.76 \pm 0.79$ & $40.54 \pm 4.02 *$ & $27.09 \pm 2.58 \#$ \\
DPP-IV nmol/g tissue & $117.9 \pm 8.47$ & $310.6 \pm 12.58^{*}$ & $182.1 \pm 24.79 \#$ \\
\hline Data are represented as mean \pm SD. & $*=$ Significant change compared to group I $(p$-value $<0.05)$. \\
n=10. & \#= Significant change compared to group II $(p$-value $<0.05)$.
\end{tabular}

Table (5): Effect of treatment with sitagliptin $(10 \mathrm{mg} / \mathrm{kg} /$ day $)$ together with high fat diet HFD for 4 week preceded by 16 weeks of HFD only on total histopathological score in albino rats.

\begin{tabular}{lccc}
\hline & $\begin{array}{c}\text { Normal } \\
\text { control }\end{array}$ & $\begin{array}{c}\text { HFD non } \\
\text { treated }\end{array}$ & $\begin{array}{c}\text { Sitagliptin } \\
\text { treated }\end{array}$ \\
\hline $\begin{array}{l}\text { Total histopathological } \\
\text { NAS score }\end{array}$ & $1.8 \pm 0.79$ & $7.6 \pm 0.52 * 5.10 \pm 0.88 \#$ \\
\hline
\end{tabular}

Data are represented as mean $\pm \mathrm{SD}$.

$\mathrm{n}=10$.

$*$ = Significant change compared to group I ( $p$-value $<0.05)$.

\# = Significant change compared to group II $(p$-value $<0.05)$.

Table (6): Effect of treatment with sitagliptin (10 mg/kg/day) together with high fat diet HFD for 4 week preceded by 16 weeks of HFD only on fibrosis score in albino rats.

\begin{tabular}{lccc}
\hline & $\begin{array}{c}\text { Normal } \\
\text { control }\end{array}$ & $\begin{array}{c}\text { HFD non } \\
\text { treated }\end{array}$ & $\begin{array}{c}\text { Sitagliptin } \\
\text { treated }\end{array}$ \\
\hline Stage 0 & $100 \%$ & $0.0 \%$ & $10 \%$ \\
Stage 1 & $0.0 \%$ & $0.0 \%$ & $60 \%$ \\
Stage 2 & $0.0 \%$ & $60 \%$ & $30 \%$ \\
Stage 3 & $0.0 \%$ & $40 \%$ & $0.0 \%$ \\
Stage 4 & $0.0 \%$ & $0.0 \%$ & $0.0 \%$ \\
\hline
\end{tabular}

Table (7): Effect of treatment with sitagliptin $(10 \mathrm{mg} / \mathrm{kg} / \mathrm{day})$, with high fat diet HFD for 4 weeks preceded by 16 weeks of HFD only on phenylephrine (PE) induced contractions of aortic rings isolated from rats of different studied groups.

\begin{tabular}{cccc}
\hline $\begin{array}{c}\text { Phenyl ephrin } \\
\text { concentration } \\
\text { ug/ml }\end{array}$ & $\begin{array}{c}\text { Normal } \\
\text { control }\end{array}$ & $\begin{array}{c}\text { HFD non } \\
\text { treated }\end{array}$ & $\begin{array}{c}\text { Sitagliptin } \\
\text { treated }\end{array}$ \\
\hline 2 & $0.21 \pm 0.01$ & $0.56 \pm 0.08^{*}$ & $0.46 \pm 0.04 \#$ \\
4 & $0.29 \pm 0.04$ & $0.98 \pm 0.06^{*}$ & $0.68 \pm 0.06 \#$ \\
8 & $0.35 \pm 0.02$ & $1.7 \pm 0.1^{*}$ & $1.1 \pm 0.01 \#$ \\
16 & $0.45 \pm 0.03$ & $1.97 \pm 0.04^{*}$ & $1.47 \pm 0.04 \#$ \\
\hline
\end{tabular}

Data are represented as mean $\pm \mathrm{SD}$.

$\mathrm{n}=10$.

$*$ = Significant change compared to group I ( $p$-value $<0.05)$.

$\#=$ Significant change compared to group II $(p$-value $<0.05)$.

For the histopathological studies Liver sections from rats fed with the regular dry rat chow (normal control group I) had normal morphological appearance with normal structure and architecture with mean total NAS score $1.8 \pm 0.79$ with no evidence of fibrotic changes with $100 \%$ of animals having (score 0) (Fig. 1). In case of feeding rats with high fat high cholesterol diet for 20 weeks (Group II) all rats developed hepatic changes consistent with severe stetaosis. All liver samples showed moderate to severe lobular inflammation with focal necrosis and hepatocellular ballooning. Hepatic inflamma- 
tion was present as demonstrated by infiltration with polymorphs and mononuclear cells, with necrotic foci were frequently observed with mean total NAS score was significantly increased compared to that of normal group (group I) (Fig. 2a). Liver sections stained with Masson stain showed extensive periportal and portal fibrosis (Fig. 2b). administration of sitagliptin orally for 4 weeks resulted in significant reduction of pathological changes induced by high fat diet feeding and improvement of histopathological scores with liver samples showing mild to moderate steatosis and less inflammation and ballooning with significant reduction of total NAS and fibrosis scores compared to non treated group II (Tables 5,6) (Figs. $3 a, b)$.

Regarding to the in vitro vascular reactivity studies, The aortic ring contraction responses to phenylephrine (PE) in different groups were obtained in grams.

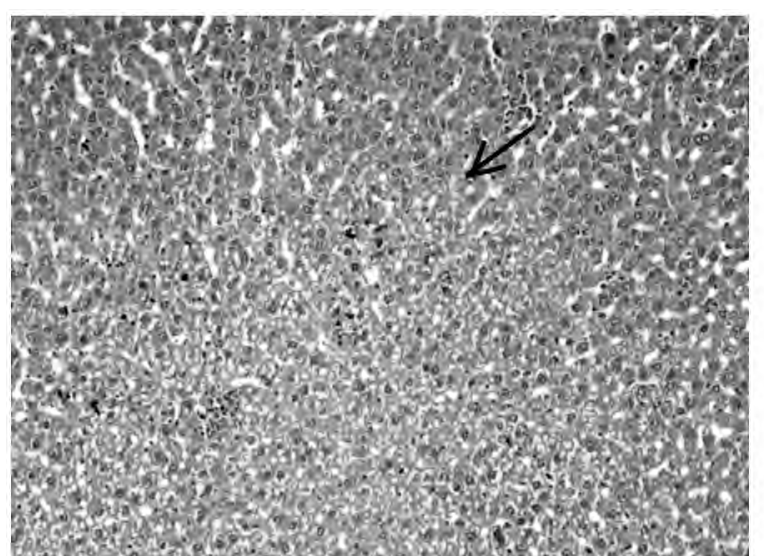

Fig. (2A): Liver section of HFD fed group II showing showing severe degree of micro and macrovescicular steatosis and severe hepatocellular ballooning with frequent foci of inflammatorycells (black arrow) (Haematoxylin \& Eosin x200).

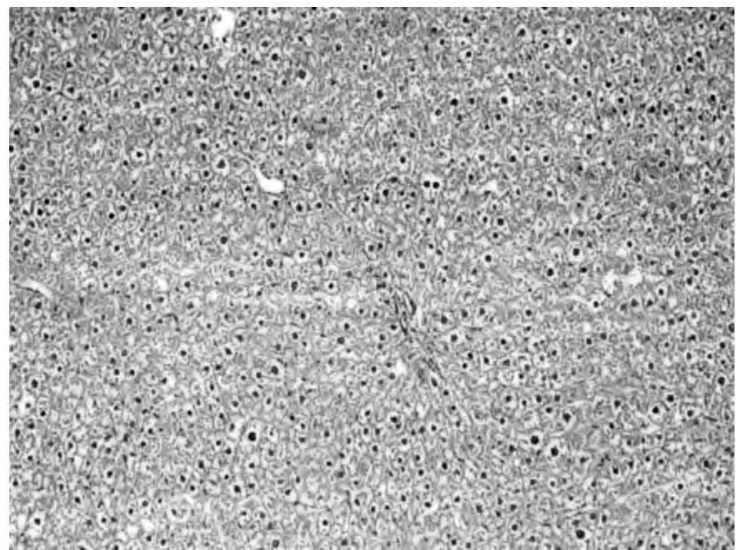

Fig. (3A): Liver sections of rats treated with sitagliptin (group III) showing improved inflammation and moderate steatosis $(\mathrm{H} \& \mathrm{E} \times 100)$
Induction of NAFLD with high fat high cholesterol diet for 20 weeks (group II) resulted in significant increase of the mean aortic ring contractile response to different concentrations of PE compared to normally fed rats of group I. Administration of sitagliptin for 4 weeks resulted in significant reduction in PE induced contractions compared to HFD non treated group II (Table 7).

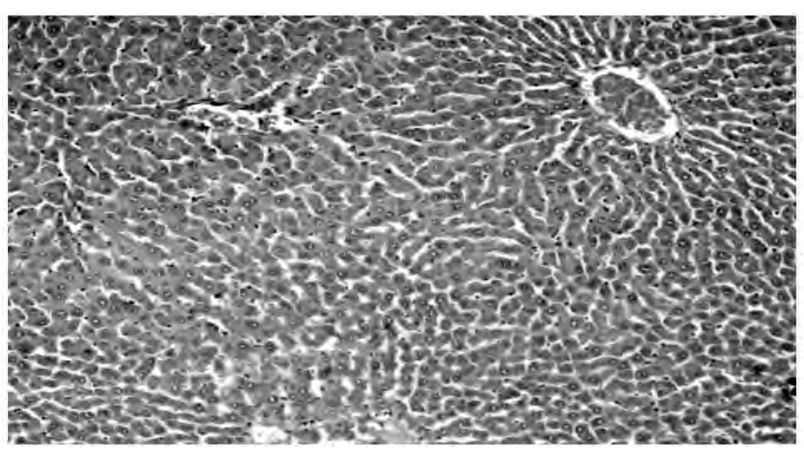

Fig. (1): Liver section of control group I showing normal structure and architecture (Haematoxylin \& Eosin $\mathrm{x} 100)$.

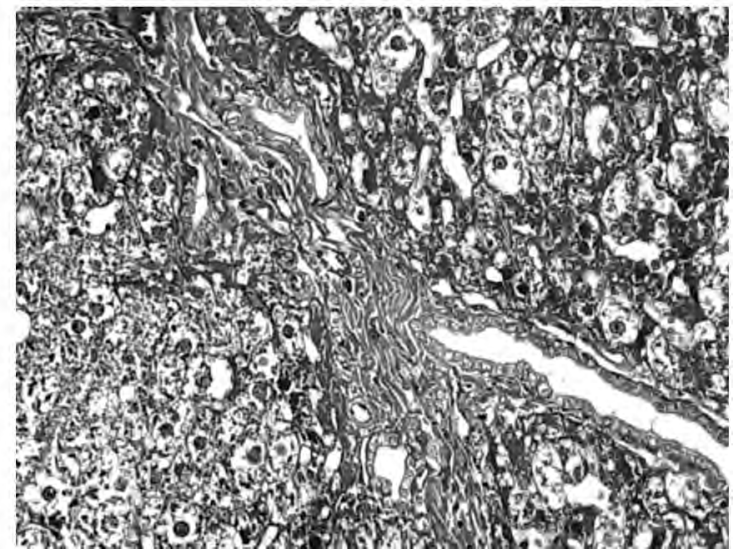

Fig. (2B): Liver section of HFD fed group II showing marked portal fibrosis (yellow arrow) masson trichom stain $\mathrm{x} 100)$.

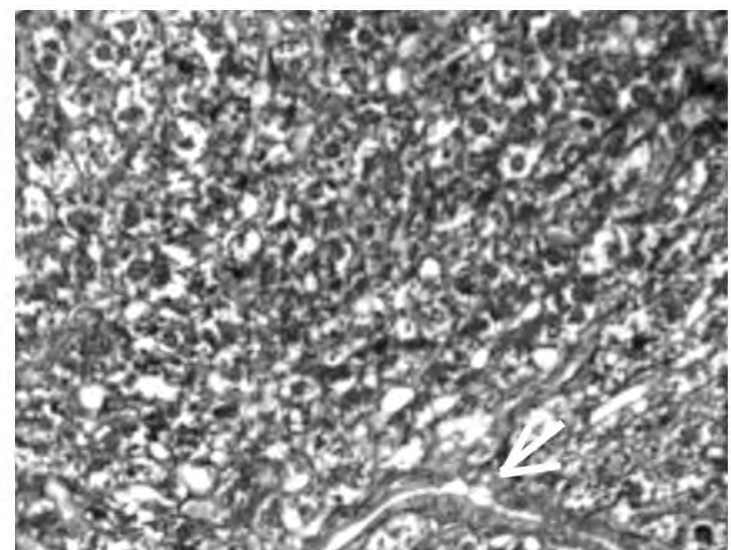

Fig. (3B): Liver sections of rats treated with sitagliptin showing mild perisinasoidal fibrosis (yellow arrow) (masson stain $\mathrm{x} 100$ ) 


\section{Discussion}

The nonalcoholic fatty liver disease (NAFLD) is defined as the presence of hepatic steatosis (abnormal lipid accumulation in hepatocytes), in the absence of secondary causes of hepatic fat accumulation such as significant alcohol consumption [11]. A subgroup of NAFLD patients has liver cell injury and inflammation in addition to excessive fat (steatohepatitis). The latter condition is called non-alcoholic steatohepatitis (NASH). While the simple steatosis seen in NAFLD does not correlate with increased short-term morbidity or mortality, progression of this condition to that of NASH dramatically increases the risks of cirrhosis, liver failure, and hepatocellular carcinoma (HCC) [12]. Glucagon like peptide-1 (GLP-1) is an incretin hormone secreted from intestinal L cells in response to nutrient ingestion, and has various bioactivities including glucose dependent insulin secretion, promoting $\beta$-cell survival, inhibiting glucagon secretion from a-cell, slowing gastric emptying and controlling food intake. These effects help to maintain an euglycaemic level and are beneficial for weight control; however under physiological conditions the intact active GLP-1 is quickly degraded by dipeptidyl peptidase-4 (DPP-4) into the inactive GLP-1. Therefore DPP-4 inhibitors, were developed and have been widely accepted in treatment of T2DM [13,14]. In the present study the effect of sitagliptin, was tested on different features of rat model of non-alcoholic fatty liver disease (NAFLD) induced by high fat diet (HFD) feeding for 20 weeks.

HFD feeding of rats for 20 weeks resulted in development of rat steatohepatitis as documented from the histopathological and biochemical tests.

In the present study, rats received oral Sitagliptin for 4 weeks with HFD after 16 weeks of HFD only resulted in significant reduction of the mean body weight compared to that of the corresponding HFD fed non-treated groups Sitagliptin adminsteration for 4 weeks in HFD fed rats resulted in significant reduction of epidydimal fat weight and liver index (LI) compared to that of the corresponding HFD fed non treated groups.

NAFLD/NASH is now considered one of the hepatic manifestations of metabolic Syndrome [15] which was reflected in the animal model of NAFLD used. The results of the present work was in accordance to other studies where Buettner, Schölmerich and Bollheimer observed that prolonged offer of a lipid-rich diet induces weight gain in susceptible rats compared to control. According to these authors, the induction of obesity is more effective when the high-fat diet is started at a young age and is continued for several weeks [16]. Also, Seif El-Din et al., reported that body weight significantly increased with the high-fat diet, this might be due to a metabolic imbalance of carbohydrate, protein, and fat [17]. It was also noted that the body weight and the liver index in HFD fed untreated groups were significantly higher than normally fed groups. the results of the present study were in agreement with the study which reported that body weight of the mice was significantly lower in the sitagliptin group compared with the control in non-alcoholic steatohepatitis in FLS-ob/ob male mice [18]. The liver weight and liver weight/body weight ratio in the sitagliptin group also reduced. Increased GLP1 action by pharmacological DPP-4 inhibition partly accounts for reduced adiposity in weight gaining mice through improving lipid metabolism [19]. DPP-4 is highly expressed in various types of adipose tissue such as visceral and to a lesser extent, subcutaneous fat tissue [20]. Adipocytic DPP4 expression increases according to adipocytic differentiation [21]. This evidence provides a potential strong linkage between DPP4 and adiposity. On the other hand some of the experimental data in rodents support the possibility of weightindependent effects of incretin therapies on hepatic steatosis. In DPP-4 deficient rats, weight is not significantly affected compared to controls while the improvements in steatosis were notable [22] In contrary of the present study Sujishi et al., found that there was insignificant difference in the weight of sitagliptin treated mice versus control untreated high fructose diet fed ob/ob mice [23], treatment with sitagliptin, resulted in significant reduction of serum levels of total cholesterol compared to high fat fed non treated groups. Regarding triglycerides serum level there was significant reduction also compared to the corresponding HFD fed non treated group. Significant reduction of transaminases ALT and AST levels was reported in sitagliptin treated group compared to the corresponding HFD fed non-treated group.

These results were in accordance with Sujishi et al study which found that plasma AST and ALT levels were significantly lower in mice fed HFD containing sitagliptin. These mice also showed lower plasma and hepatic TG which is a hallmark for hepatic steatosis [23]. The underlying mechanism of these beneficial effects has been investigated by Ohyama et al., study in which the DPP4-inhibitor MK-0626 attenuates hepatic steatosis and improved lipid profile by enhancing AMPK activity, inhibiting hepatic lipogenic gene expression, increasing triglyceride secretion from liver and elevating serum 
adiponectin levels [24]. Hsieh et al., also suggested that DPP 4 inhibitors augment the level of GLP1 receptors thus reduce secretion of triglycerol, cholesterol, and apolipoprotein B-40 from intestine [25]. Notably, another DPP-4 inhibitor, vildagliptin, is reported to reduce the prandial triglyceride response to fat-rich meal intake [26]. Furthermore, sitagliptin in combination with metformin reduced cholesterol and triglyceride levels. Recently, in a comprehensive retrospective review of 459 type 2 diabetic patients, treated with DPP4-inhibitors, it was shown that DPP4 inhibitors improved the abnormality of the liver transaminases AST and ALT independent of HbA1c and body weight [27]. On the other hand Onoyama et al., reported that serum ALT and AST levels showed insignificant reduction compared to untreated nonalcoholic steatohepatitis FLS-ob/ob male mice [18]. Also hepatic total cholesterol and triglyceride contents in the sitagliptin group were lower compared with the control group however, not significant. Regarding the effects of sitagliptin on glycemic control and insulin resistence, the results of the present work showed significant reduction of fasting glucose levels Regarding serum insulin levels, significant reduction was observed with sitagliptin treatment compared to non treated groups. In NAFLD, type 2 diabetes, or metabolic syndrome, insulin resistance develops because of a defect in insulin signal transduction mechanism [28]. So, circulating insulin concentration fails to induce glucose uptake into the cells and the hyperglycemia develops. To compensate for the hyperglycemia, pancreas secretes more insulin leading to hyperinsulinemia [29].

Multiple biochemical, metabolic and signal transduction pathways contribute to insulin resistance. It was found that protein glycation may play role in insulin resistance by a variety of mechanisms, including generation of tumor necrosis factor-alpha, direct modification of the insulin molecule leading to its impaired action, generation of oxidative stress and impairment of mitochondrial function [30]. So that the beneficial effect of sitagliptin is mostly due to its glycemic control with consequent improvement of insulin resistance. These results were in accordance with other studies which noted that Sitagliptin significantly improved hyperglycemia, insulin resistance compared with the controls under the identical dietary intake. The inhibition of DPP-4 by sitagliptin led to the attenuation of incretin degradation, consequently increasing insulin and reducing blood glucose levels $[22,18]$. Shirakawa et al., explained the improvement of insulin resistence in sitagliptin treated mice by its ability to reduce expression of sterol regulatory element-binding protein-1c, stearoyl-CoA desaturase- 1 , and fatty acid synthase, and increased expression of peroxisome proliferator-activated receptor- $\alpha$ in the liver [22] . In Kirino et al., study, it was reported that DPP4-deficient rats were resistant to developing hyperglycaemia owing to lower food intake and higher insulin sensitivity [31] . Another study conducted by Sujishi et al., reported that the plasma glucose levels were lower, but the plasma insulin levels were not in sitagliptin high-fructose diet-fed ob/ob mice [23]. Also Chae et al noted that both exenatide and evogliptin (new DPP4I) did not significantly improve hyperinsulinemia in HFD mice. In the present study prophylactic administration of sitagliptin restored hepatic reduced GSH with significant increase in its levels compared to that of the corresponding HFD fed non treated group [32]. For MDA levels, use of sitagliptin resulted in significant increase compared to non treated groups. Oeseburg et al., published evidence for a protective effect of DPP-4 inhibition on oxidative stress-induced DNA damage in Zucker diabetic fatty rats and detected reduced oxidative stress under DPP-4 inhibitor therapy in animal models of type 1 diabetes cardiac ischemia /reperfusion-injury, chronic myocardial infarction and Parkinson's diseases [33]. Furthermore, limited data are available on the reduction of oxidative stress by DPP-4 inhibition in humans. Increased oxidative stress is largely caused by hyperglycemia induced inappropriate activation and accumulation of advanced glycation end products (AGE) which are prooxidatives, proinflammatory and profibrotic. Proteins are usually glycated through their lysine residues. In humans, histones in the cell nucleus are richest in lysine, and therefore form the glycated protein. The accumulation of AGE also contributes to endoplasmic reticular stress leading to insulin resistance [43] . AGE-induced ROS formation induces release of DPP-4 from endothelial cells (ECs), initiating a positive feedback loop whereby DPP-4 induces expression of receptors of AGE (RAGE) to further exacerbate AGE effects in ECs [35]. Furthermore, DPP-4I treatment significantly inhibits the AGE- induced ROS generation. In the present study administration of Sitagliptin resulted in significant antifibrotic effects with significant reduction of hepatic TGF- $ß$ levels compared to the corresponding HFD fed non-treated group. It has been reported that the serum DPP4 activity was augmented intetrachloromethane-induced cirrhotic rats. Furthermore, it has also been stated that the serum DPP4 activity might be an indicator of the severity and progression of liver cirrhosis [36] DPP4 also participates in the fibroblast activation, and plays a role in hepatocyte extracellular matrix 
in small groups of diabetic patients demonstrated that DPP-4I improved the levels of liver transaminases and liver fat (steatosis) Yilmaz found a decrease in ballooning and non-alcoholic steatohepatitis scores in post-treatment liver biopsies [41]. In the majority of publications, the authors postulate that these beneficial actions were mediated through potentiation of direct GLP-1 actions on hepatocytes.

DPP-4 inhibitor has been reported to improve hepatic steatosis in mice and humans. Itou et al., experienced a case of refractory NAFLD that was successfully treated with sitagliptin, a DDP-4 inhibitor [42]

The effect of DPP-4 inhibitors on blood pressure is contradictory. In the present study there was insignificant reduction of the mean value of the mean arterial pressure (MAP) with sitagliptin treatment. This result was in accordance with Matsu et al., study which reported that the DPP-4I vildagliptin showed no influence on blood pressure in hypertensive fatty rats [43]. More over Koren et al., in a clinical study conducted on 40 diabetic patients; concluded that treatment of these patients with sitagliptin at a dose change in blood pressure monitoring all through the study [44]. Moreover Monami et al., in a meta-analysis of randomized clinical trials concluded that treatment of type 2 diabetic patients with DPP-4I inhibitors was associated with decrease in arterial blood pressure and cardiovascular complications. The present study demonstrated that treatment with sitagliptin improved the endothelial dysfunction induced by HFD [45].

The eNOS-NO system is thought to be responsible for endothelial dysfunction in diabetes. Endothelial dysfunction is a predictor for cardiovascular events in patients with type 2 diabetes. In some studies it was found that GLP-1 has some vasodilatory action and Sitagliptin significantly improved endothelial function and inflammatory state in patients with coronary artery disease and uncontrolled diabetes mellitus, DPP4 inhibitors also exert vascular protective properties, including anti-inflammatory and anti-atherosclerotic effects which may explain their ability to induce vascular relaxation [46]. In the setting of obesity/T2DM, endothelial dysfunction and arterial stiffness may result from multiple factors including insulin resistance, oxidative stress, dyslipidemia, adipose tissue dysfunction. These components are modulated by DPP-4I and thus may contribute to CVD protection [47].

\section{Conclusion:}

DPP4Is are potent highly selective inhibitors of DPP4 approved for treatment of T2DM as either monotherapy or in combination. To date, most DPP4Is have good safety and tolerability with low incidence of adverse events. The abnormal increase in circulating DPP4 levels in individuals who are obese and diabetic underscores the significance of targeting DPP4 as therapeutic strategy. The results of the present work recommend the prophylactic use of sitagliptin for prevention of NAFLD progression in diabetic and prediabetic patients.

\section{References}

1- ANGULO P. : GI epidemiology: Nonalcoholic fatty liver disease. Alimentary Pharmacology \& Therapeutics, 25 (8): 883-889, 2007.

2- LOOMBA R. and SANYAL A.J.: The global NAFLD epidemic. NatureReviews Gastroenterology and Hepatology, 10 (11): 686-690, 2013.

3- VANNI E., BUGIANESI E., KOTRONEN A., DE MINICIS S., YKI-JÄRVINEN H. and SVEGLIATI-BARONI G.: From the metabolic syndrome to NAFLDor vice versa?. Digestive and liver Disease, 42 (5): 320-330, 2010.

4- DHILLON S.: Sitagliptin: A review of its use in the management of type 2diabetes mellitus. Drugs, 70 (4): 489-512, 2010.

5- CUI, J., PHILO L., NGUYEN P., HOFFLICH H., HERNANDEZ C., BETTENCOURT R. and HAUFE W.: Sitagliptin vs. placebo for non-alcoholic fatty liver disease: A randomized controlled trial. Journal of Hepatology, 65 (2): 369-376, 2016.

6- FERREIRA L., TEIXEIRA-DE-LEMOS E., PINTO F., PARADA B., MEGA C., VALA H. and SANTOS P.: Effects of sitagliptin treatment on dysmetabolism, inflammation, and oxidative stress in an animal model oftype 2 diabetes (ZDF rat). Mediators of Inflammation, 2010.

7- WANG W., ZHAO C., ZHOU J., ZHEN Z., WANG Y and SHEN C.: Simvastatin ameliorates liver fibrosis via mediating nitric oxide synthase in rats with non-alcoholic steatohepatitis-related liver fibrosis. PLo. S. One., 8 (10): e76538, 2013

8- KLEINER D.E., BRUNT E.M., VAN NATTA M., BEHLING C., CONTOS M.J., CUMMINGS O.W. and YEH, M.: Design and validation of a histological scoring system for nonalcoholic fatty liver disease. Hepatology, 41 (6): 1313-1321, 2005.

9- BRUNT E.M., JANNEY C.G., DI BISCEGLIE A.M., NEUSCHWANDER-TETRI B.A. and BACON B.R.: Nonalcoholic steatohepatitis: A proposal for grading and staging the histological lesions. The American Journal of Gastroenterology, 94 (9): 2467-2474, 1999.

10- DAMIANI C.E.N., ROSSONI L.V. and VASSALLO D.V.: Vasorelaxant effects of eugenol on rat thoracic aorta. Vascular Pharmacology, 40 (1): 59-66. 
11- AHMED M.: Non-alcoholic fatty liver disease in 2015. World Journal of Hepatology, 7 (11): 1450, 2003.

12- LABRECQUE D.R., ABBAS Z., ANANIA F., FERENCI P., KHAN, A.G., GOH K.L. and RAMOS J.F.: World Gastroenterology Organisation global guidelines: Nonalcoholic fatty liver disease and nonalcoholic steatohepatitis. Journal of Clinical Gastroenterology, 48 (6): 467-473, 2014.

13- AZUMA K., RÁDIKOVÁ Z., MANCINO J., TOLEDO F.G., THOMAS E., KANGANI C. and HE Y.: Measurements of islet function and glucose metabolism with the dipeptidyl peptidase 4 inhibitor vildagliptin in patients with type 2 diabetes. The Journal of Clinical Endocrinology \& Metabolism, 93 (2): 459-464, 2008.

14- ARMSTRONG M.J., HOULIHAN D.D., ROWE I.A., CLAUSEN W.H.O., ELBRØND B., GOUGH S.C.L. and NEWSOME P. N.: Safety and efficacy of liraglutide in patients with type 2 diabetes and elevated liver enzymes: Individual patient data meta-analysis of the LEAD program. Alimentary Pharmacology \& Therapeutics, 37 (2): 234-242, 2013.

15- FAN J.G. and FARRELL G.C.: VAT fat is bad for the liver, SAT fat is not!. Journal of Gastroenterology and Hepatology, 23 (6): 829-832, 2008.

16- BUETTNER R., SCHÖLMERICH J., and BOLLHEIMER L.C.: High-fat diets: Modeling the metabolic disorders of human obesity in rodents. Obesity, 15 (4): 798-808, 2007.

17- SEIF EL-DIN H.S., EL-LAKKANY N.M., EL-NAGGAR A.A., HAMMAM O.A., EL-LATIF H.A.A., AIN-SHOKA A.A., and EBEID F. A.: Effects of rosuvastatin and/or carotene on non-alcoholic fatty liver in rats. Research in Pharmaceutical Sciences, 10 (4): 275, 2015.

18- ONOYAMA T., KODA M., OKAMOTO T., KISHINA M., MATONO T., SUGIHARA T. and MURAWAKI Y.: Therapeutic effects of the dipeptidyl peptidase-IV inhibitor, sitagliptin, on non-alcoholic steatohepatitis in FLS-ob/ob male mice. Molecular Medicine Reports, 12 (5): 6895 6902, 2015.

19- LIU Y., WEI R. and HONG T.P.: Potential roles of glucagon-like peptide-1-based therapies in treating nonalcoholic fatty liver disease. World Journal of Gastroenterology: W.J.G., 20 (27), 9090, 2014.

20- LAMERS D., FAMULLA S., WRONKOWITZ N., HARTWIG S., LEHR S., OUWENS D.M. and HANISCH F.G.: Dipeptidyl peptidase 4 is a novel adipokine potentially linking obesity to the metabolic syndrome. Diabetes, 60 (7): 1917-1925, 2011.

21- ROSMANINHO-SALGADO J., MARQUES A.P., ESTRADA M., SANTANA M., CORTEZ V., GROUZMANN E. and CAVADAS C.: Dipeptidylpeptidase- IV by cleaving neuropeptide $\mathrm{Y}$ induces lipid acc mulation and PPAR-T expression. Peptides, 37 (1): 49-54, 2012.

22- SHIRAKAWA J., FUJII, H., OHNUMA K., SATO K., ITO Y., KAJI M. and AMO K.: Diet-induced adipose tissue inflammation and liver steatosis are prevented by DPP-4 inhibition in diabetic mice. Diabetes, 60 (4): 12461257, 2011.

23- SUJISHI T., FUKUNISHI S., II M., NAKAMURA K., YOKOHAMA K., OHAMA H. and HIGUCHI K.: Sit- agliptin can inhibit the development of hepatic steatosis in high-fructose diet-fed ob/ob mice. Journal of Clinical Biochemistry and Nutrition, 57 (3): 244-253, 2015.

24- OHYAMA T., SATO K., YAMAZAKI Y., HASHIZUME H., HORIGUCHI N., KAKIZAKI S. and YAMADA M.: MK-0626, a selective DPP-4 inhibitor, attenuates hepatic steatosis in ob/ob mice. World Journal of Gastroenterology: W.J.G., 20 (43): 16227, 2014.

25- HSIEH J., LONGUET C., BAKER C.L., QIN B., FEDERICO L.M., DRUCKER D.J. and ADELI K.: The glucagon-like peptide 1 receptor is essential for postprandial lipoprotein synthesis and secretion in hamsters and mice. Diabetologia., 53 (3): 552-561, 2010.

26- MATIKAINEN N., MÄNTTÄRI S., SCHWEIZER A., ULVESTAD A., MILLS D., DUNNING B.E. and TASKINEN M.R.: Vildagliptin therapy reduces postprandial intestinal triglyceride-rich lipoprotein particles in patients with type 2 diabetes. Diabetologia, 49 (9): 2049-2057, patients with type 2 diabetes. Diabetes, Obesity and Metabolism, 10 (10): 959-969, 2006.

27- KANAZAWA I., TANAKA K.I. and SUGIMOTO T.: DPP-4 inhibitors improve liver dysfunction in type 2 diabetes mellitus. Medical Science Monitor, 20: 16621667, 2014.

28- DAVIS L.M., PEI Z., TRUSH M.A., CHESKIN L.J., CONTOREGGI C., MCCULLOUGU K., et al.: Bromocriptine reduces steatosis in obese rodent models. J. Hepatol., 45: 439-44, 2006.

29- NADE V.S., KAWALE L.S., TODMALU. and TAJANPURE B.A.: Study of bromocriptine effect on cardiovascular complications associated with metabolic syndrome in fructose fed rats. Indian J. Pharmacol. Nov-Dec., 44 (6): 688-69, 2012.

30- SONG F and SCHMIDT A.M.: Glycation and Insulin Resistance. Arteriosclerosis, thrombosis, and Vascular Biology, 32 (8): 1760-1765, 2012.

31- KIRINO Y., SATO Y., KAMIMOTO T., KAWAZOE K., MINAKUCHI K. and NAKAHORI Y. Interrelationship of dipeptidyl peptidase IV (DPP4) with the development of diabetes, dyslipidaemia and nephropathy: A streptozotocin-induced model using wild-type and DPP4-deficient rats. Journal of Endocrinology, 200 (1): 53-61, 2009.

32- CHAE Y.N., KIM T.H., KIM M.K., SHIN C.Y., JUNG I.H., SOHN Y.S. and SON M.H.: Beneficial effects of evogliptin, a novel dipeptidyl peptidase 4 inhibitor, on adiposity with increased Ppargc1a in white adipose tissue in obese mice. PloS. One., 10 (12): e0144064, 2015

33- OESEBURG H., DE BOER R.A., BUIKEMA H., VAN DER HARST P., VAN GILST W.H. and SILLJÉ, H.H.: Glucagon-Like Peptide 1 Prevents Reactive Oxygen Species-Induced Endothelial Cell Senescence Through the Activation of Protein Kinase A. Arteriosclerosis, thrombosis, and Vascular Biology, 30 (7): 1407-1414, 2010.

34- DATLA S.R. and GRIENDLING K.K.: Reactive oxygen species, NADPH oxidases, and hypertension. Hypertension., 56 (3): 325-330, 2010.

35- ISHIBASHI Y., MATSUI T., MAEDA S., HIGASHIMOTO Y. and YAMAGISHI S.I.: Advanced glycation end products evoke endothelial cell damage by stimulating 
soluble dipeptidyl peptidase-4 production and its interaction with mannose 6-phosphate/insulin-like growth factor II receptor. Cardiovascular Diabetology, 12 (1): 125 , 2013.

36- LAKATOS P.L., FIRNEISZ G., BORCSICZKY D., ZALATNAI A., SELMECI L. and SZALAY F.: Elevated serum dipeptidyl peptidase IV (CD26, EC 3.4. 14.5) activity in experimental liver cirrhosis. European Journal of Clinical Investigation, 30 (9): 793-797, 2000.

37- WANG X.M., YU D.M.T., MCCAUGHAN G.W. and GORRELL M.D.: Fibroblast activation protein increases apoptosis, cell adhesion, and migration by the LX-2 human stellate cell line. Hepatology, 42 (4): 935-945, 2005.

38- KAJI K., YOSHIJI H., IKENAKA Y., NOGUCHI R., AIHARA Y., DOUHARA A. and YANASE K.: Dipeptidyl peptidase-4 inhibitor attenuates hepatic fibrosis via suppression of activated hepatic stellate cell in rats. Journal of Gastroenterology, 49 (3): 481-491, 2014.

39- IDETA T., SHIRAKAMI Y., MIYAZAKI T., KOCHI T., SAKAI H., MORIWAKI H. and SHIMIZU M.: The dipeptidyl peptidase-4 inhibitor teneligliptin attenuates hepatic lipogenesis via AMPK activation in non-alcoholic fatty liver disease model mice. International Journal of Molecular Sciences, 16 (12): 29207-29218, 2015.

40- Akaslan S.B., Degertekin C.K., Yilmaz G., Cakir N., Arslan M. and Toruner F.B.: Effects of sitagliptin on nonalcoholic fatty liver disease in diet-induced obese rats. Metabolic syndrome and related disorders, 11(4): 243$250,2013$.

41- YILMAZ Y.: Review article: Is non-alcoholic fatty liver disease a spectrum, or are steatosis and non-alcoholic steatohepatitis distinct conditions?. Alimentary Pharmacology \& Therapeutics, 36: 815-823. doi: 10.1111/apt. 12046, 2012.
42- ITOU M., KAWAGUCHI T., TANIGUCHI E., ORIISHI T. and SATA M.: Dipeptidyl peptidase IV inhibitor improves insulin resistance and steatosis in a refractory nonalcoholic fatty liver disease patient: A case report. Case Reports in Gastroenterology, 6 (2): 538-544, 2012.

43- Matsui T., Nishino Y., Takeuchi M. and Yamagishi S.I.: Vildagliptin blocks vascular injury in thoracic aorta of diabetic rats by suppressing advanced glycation end product-receptor axis. Pharmacological Research, 63 (5): 383-388, 2011.

44- KOREN S., SHEMESH-BAR L., TIROSH A., PELEG R.K., BERMAN S., HAMAD R.A., et al.: The effect of sitagliptin versus glibenclamide on arterial stiffness, blood pressure, lipids, and inflammation in type 2 diabetes mellitus patients. Diabetes. Technol. Ther., Jul., 14 (7): 561-7. doi:10.1089/dia.2011.0296. Epub 2012 Apr 18, 2012.

45- MONAMI M., AHREN B., DICEMBRINI I. and MANNUCCI E.: Dipeptidyl peptidase-4 inhibitors and cardiovascular risk: a meta-analysis of randomized clinical trials. Diabetes, Obesity and Metabolism., 15: 112-120, 2013.

46- MATSUBARA J., SUGIYAMA S., SUGAMURA K., NAKAMURA T., FUJIWARA Y., AKIYAMA E. and MAEDA H.: A dipeptidyl peptidase-4 inhibitor, desfluoro-sitagliptin, improves endothelial function and reduces atherosclerotic lesion formation in apolipoprotein e-deficient mice. Journal of the American College of Cardiology, 59 (3): 265-276, 2012.

47- AROOR A.R., SOWERS J.R., JIA G. and DEMARCO V.G.: Pleiotropic effects of the dipeptidylpeptidase-4 inhibitors on the cardiovascular system. American Journal of Physiology-Heart and Circulatory Physiology, ajpheart00209, 2014. 


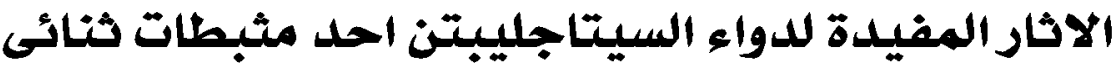

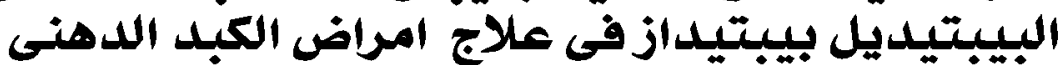

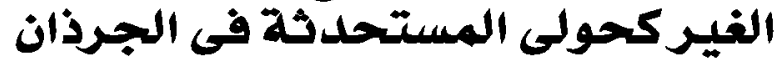

مرض الكبد الدهنى غير الكحولى يعتبر حاليا احد المرتبط بشدة بمتلازمة التمثيل الغذائي، اصبع بثكل متزايد مبيا رئيسيا من

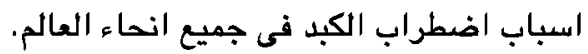

دواء السيتاجليتن الذى يعمل عن طريق تثبيت ثثائى بيبتيديل بيتيداز -ع مما يمنع تكثير بعض البيتيدات بما فيهم الانكريتين

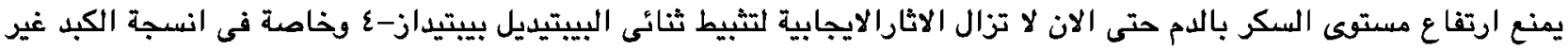

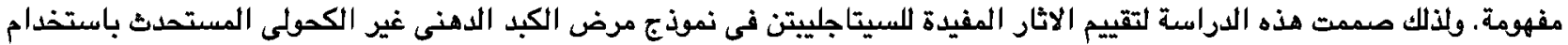
نظام غذائى عالى الدهون فئى الجرذان. تم استخدام عدد • ب جرذا متقاريين فى الوذن والسن موزعين على ب مجموعات كل مجموعة تشمل • اجرذا كما يلى : 1 Y - مجموعة ضابطة تغذت على غذاء عالى الدهون. r- ب مجموعة معالجة بلواء السيتاجلييتن

نتائج هذه الدراسة وضحت وجود زيادة ذات دلالة احصائية في وذن وضغط الدم للجرذان التى تغذت على الغذاء عالى الدهون

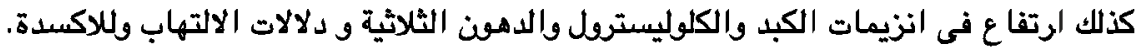

بينما نجيح الاستخدام العلاجى بالسيتاجليبتن في خفض الونن بصورة ذات دلالة احصائية وتصسن في نتائج التصاليل والصسوة

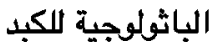

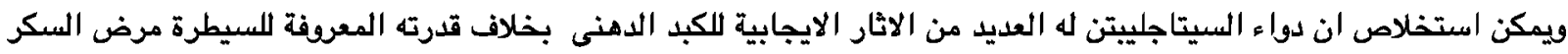

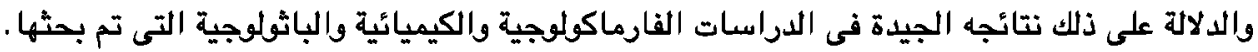

